\title{
Association of Apo-B gene Polymorphism with adiposity
}

\author{
Dr.Fahmida Khatoon ${ }^{1}$, Abd-Elnaser Badawy ${ }^{2}$,Dr.Shiza Batool ${ }^{3}$, \\ Dr. Farhan Essa Abdullah ${ }^{4}$ Zahid Balouch ${ }^{5}$ DR.Saima Omer ${ }^{6}$ \\ Assistant Professor,Biochemistry Department,United Medical and Dental College. Karachi, $P K^{l}$ \\ Professor of Biochemistry department,Faculty of medicine,Mansoura university 4 \\ Assistant Professor, Aziz Fatima medical and Dental College ,Faisalabad, $P K^{3}$ \\ Associate Professor, Liaquat College Of Medicine and Dentistry ${ }^{4}$ \\ Lecturer, Dada Bhoy Institute of Higher Education, $P K^{5}$ \\ Lecturer ,Physiology Dept.Northern Boarder University ${ }^{6}$
}

\begin{abstract}
Background: Hypertension, Diabetes Mellitus and Cardiovascular Diseases are the most common and prevalent disease worldwide. Atherosclerosis particularly severe atherosclerosis and its complication are the underlying process responsible for almost all cases of ischemic heart disease. Atherosclerosis produces significant cardiac morbidity such as angina ,myocardial infarction, Ischemic cardiomyopathy and sudden death. Other risk factors includes age, sex and heredity as modified risk factors. Genetically determined risk factor such as hyperlipidemia is first one in this regard.
\end{abstract}

Objective: To Determine the correlation of apolipoprotein with lipid profile

Methods: The study was carried out in Fifty four patients of age between 25 to 65 years having hypercholesterolemia and 54 healthy male having normal cholesterol levels. Blood samples were drawn after informed consent. Glucose tolerance test was done and lipid profile after over night fast were detected.2ml of whole bloodwas kept for genetic analysis. Isolated DNA was then polymerized to determine the genotypes at EcoR1 polymorphic site of ароB by Polymerase chain reaction.Data analysis was done by SPSS version 18.

Results: Allelic frequencies of homozygous and heterozygous individuals were obatainedby gene counting.By comparing them its was found that there was no significant difference between the two groups.

Conclusion: There was no correlation of allelic frequencies of polymorphism between hperlipidemic and normolipidemic subjects.

Key Words: PCR, Polymerase Chain Reaction, EcoR1,Polymorphism

\section{Introduction}

Cardiovascular Diseases are one of the leading cause of death world wide .While the term technically refers to any disease that affects the cardiovascular system. An estimated 16.7 million or $29.2 \%$ of total global deaths-results from the various forms of cardiovascular disease (CVS), many of which are preventable by action on the major primary risk factors: unhealthy diet, lack of physical activity, and smoking etc. Other risk factors as evident from by the observation of Cornfield and Mitchell (1969) including age, sex and heredity(1). Osler was one of the first who emphasized the importance of genetic factor in pathogenesis of coronary artery disease. The aggregation is largely due to clustering of genetically determined risk factors such as hyperlipidemia, Diabetes Mellitus and hypertension (2). But it has also been that many of coronary heart disease have none of these factors. Hyperlilpidemia is the most important risk for atherosclerosis, as it affects mainly larger arteries while hypertension affects mainly smaller vessels. These lipid include Cholesterol, cholesterol ester , phospholipids and triglycerides. They are transported in the blood as part of large molecules called lipoproteins..There are five major families of blood (plasma) lipoprotein named ,Chylomicrons, vary low density-lipoproteins(VLDL), Intermediate-density lipoprotein(IDL), Low-density lipoprotein (LDL) and High density lipoprotein(HDL). Some research associate suggested that protein part of lipoprotein play crucial role in discriminating the atherosclerotic patients from the control, rather than lipid component (3). This protein part is called apoprotein or apolipoprotein. Studies to determine the relationship of apoprotein with atherosclerosis should be carried out.Apo-lipoprotein regulate lipoprotein metabolism, binds and transports lipids, react with tissue receptors and are genetic disorder.Apolipoprotein discovered by Berg et al in 1963 (4).Multiple studies revealed that the association of the abnormal levels of different lipoprotein and the vascular disease is not consistent.But it is found that abnormalities of LDL cholesterol is associated mainly atherosclerosis and peripheral vascular disease. Recent lipid profile studies have shown that shown that serum levels of apolipoprotein B (ApoB) are better determining markers of risk of vascular diseases. ApoB exist in human plasma, as two isoforms, apo B48 and B-100 is the major physiological ligand for LDL receptor.It is the largest manomeric protein sequenced so far, containg 4536 amino acid residues $(5,6,7)$.Its gene has been mapped on the short arm of chromosomes 2, with an approximate length of 43 kilo bases and 29 exons (8).Mutations occurring 
in the apo B gene can alter blood cholesterol level. Two mutations in the apo B gene have been associated with elevated blood cholesterol. An association between elevated Triglycerides and the absence of the EcoR1 cutting site has been reported in coronary heart disease patients and in healthy males $(9,10,11)$. In our population, individual homozygous for the EcoR1 restriction site had slow LDL catabolic rates associated with high LDL and total cholesterol values. In another study DNA polymorphism (EcoR1) of APO-B and its relationship with vascular dementia or Alzheimer disease and concluded that total cholesterol and LDL cholesterol levels are lower in Alzheimer disease patients than in vascular dementia patients and in elderly control $(12,13,14)$ In dementia patients with ApoB, EcoR1 R+R- genotype had increased total cholesterol and LDL cholesterol levels than R+R+ homozygotes. In 2000 Tania studied the role of polymorphism and mutations of Apo B particle as etiologic factors of hypercholesterolemia in a population of moderately hypercholesterolemia individuals. Several restriction fragment length polymorphisms (RFLP) in the Apo B gene have been defined (15). Advances in molecular cardiology have revealed a number of single nucleotide polymorphism associated with atherosclerosis and contribute to be a risk factor for cardiovascular diseases.

Aim and Objective:

To study the EcoR1 Polymorphism of Apo B gene

\section{Sample Collection.}

\section{Material and Methods.}

After an informed consent, blood samples were collected by venipuncture under aspetic condition in EDTA vials from subjects fulfilling the inclusion and exclusion criteria.All sample were collected in morning after an overnight fasting and $2 \mathrm{ml}$ of whole blood were kept for kept for genetic analysis and rest was kept for lipid profle and blood glucose level.

\section{Inclusion criteria/Exclusion Critaria:}

Patients of age between 25 to 65 , with the total cholesterol more than $250 \mathrm{mg} / \mathrm{dl}$ were included as a case. And patient having Diabetes, hypertension or hyperglycemia or taking drugs were excluded. Healthy subjects between age 25 to 65 with total cholesterol less than $200 \mathrm{mg} / \mathrm{dl}$ and triglyceride less than $200 \mathrm{mg} / \mathrm{dl}$ were taken as control. Glucose tolerance test according to standard W.H.O guidelines was done on every patient to exclude patients with Diabetes.

TG levels by choloroform sialiac acid method and serum glucose by Glucose oxidase-peroxidase enzymatic method. High density lipoprotein level were calculated by precipitation method.This method involves combination of ultracentrifugation to remove chylomicron and VLDL and precipitation with heparin MncL2 to remove IDL,LDL ,Lpa leaving HDL. Low density lipoprotein and vary low density lipoprotein by Friedwald formulae.

\section{DNA Isolation.}

Blood sample of $2 \mathrm{ml}$ was collected in EDTA vials for genetic analysis-genomic DNA was isolated using whole blood DNA isolation kit by standard method.Genomic DNA was analysed on $1 \%$ agarose gel and observed under UV transilluminator. Isolated DNA was then polymerized to determine the genotypes at EcoR1 polymorphic site of apoBby polymerase chain reaction by using site specific primers and using PCR master mix kits. For EcoR1 Site primers are

Farward primer (F) 5'- CTG AGA GAA GTG TCT TCG AAG -3'

Reverse primer ( R ) 5'- CTC GAA AGG AAG TGT AAT CAC -3'

Agarose gel was prepared to analyse PCR results and sample were loaded on to $1.5 \%$ agarose gel and seen under UV transilluminator.PCR products for 400bp was to be amplified detected by comparing with Ladder.

\section{Restriction Digestion}

Restriction digestions of amplicons was done us in restriction enzyme EcoR1 follwed by electrophoresis of the reaction mix of restriction endonuclease digestion on $1.2 \%$ agarose gel in TAE buffer at a contant voltage of 100V.ss DNA bands thus separated are Visualised on UV transilluminators. For the EcoR1 site, a 400bp fragement was digested with EcoR1 into two fragments of $223 \mathrm{bp}$ and $257 \mathrm{bp}$ in the presence of cutting site (E+allele).

\section{Discussion}

Table 4 Shows that there was no significance differences in the genotype and allele frequencies of $\mathrm{E}$ coR1 polymorphism between hyperlipidemic and normolipidemic subjects. The findings are similar to the observations made in a Caucasians population in USA, Although the apo-B gene polymorphism did not have any significance on the lipid levels, there was an association of IX and R1allele with CHD. Association of the $\mathbf{X}$ + allele and TC, TG, and LDLc levels in Caucasians population has been demonstrated repeatedly. Similar 
finding are also demonstrated in Ascian Indians settled in Singapore, where the X+ allele was significantly associated with high levels of serum TC,TG and low HDL-c. Renges at el showed that in Asian Indian in $\mathrm{UK}, \mathrm{X}+$ allele was associated with a low HDL-c level(16).

There may be several reasons for the differences observed in various studies. A simple explanation could be that the population studied by Saha at el and Renges et al $(16,17)$. were genetically distinctive , consisting of Indian from southern states of Indian and from the state of Punjab ,respectively. Moreover, gene environment interplay may also account for the differential data since there may be substantial differences in the diet and life style of Indians settled in other countries when compared to the north Indian population studied by us. Further the sample size of current study being small, larger study would answer the questions in a more definitive manner. The RFLP detected by Xba1 is due to a linkage disequilibrium with ins/del polymorphism, which causes an amino acid change in a single peptide of the apo-B gene. Absence of an association between EcoR1 polymorphism of apo B.

The RFLP detected with EcoR1 is due to single base pair change in coding region of the gene, which is known to cause an amino acid change in the apo-B by itself. This phenomenon may explain the general concurrence of our finding with other workers regarding correlation between EcoR1 polymorphism and serum lipid levels with E-allele has been rarely described, except in a study of Canadian population.

Results:

Apolipoprotein $-\mathrm{B}(\mathrm{ApoB})$ is involved in assembly and secretion of chylomicron from small intestine and vary low density lipoprotein cholesterol VLDL-c from liver. The apo-B is located on the short arm of chromosome 2. Out of total 104 subject under the age of 25 to 65,54 had hyperlipidemia were named as group I and 54 were normolipidemic were named as group II. Table 1 shows Oligonucleotide primer used for the amplification.

\begin{tabular}{|l|l|}
\hline Primers & Sequence \\
\hline EcoR1Farward & (F) 5'- CTG AGA GAA GTG TCT TCG AAG -3' \\
\hline EcoR1Reverse & ( R ) 5'- CTC GAA AGG AAG TGT AAT CAC -3' \\
\hline
\end{tabular}

Table:1 Oligonucleotide primer used for the amplification

Apo B gene was amplified using the primer specific for the segment of gene Apo B gene which include a single EcoR1 site as shown in Table:2

\begin{tabular}{|l|l|l|}
\hline Primers & Expected Band Size & Observed Band size \\
\hline EcoR1 & $400 \mathrm{pb}$ & Approx 400bp \\
\hline
\end{tabular}

Table 2: Oligonucleotide primer used for the amplification

\section{Restriction Digestion:}

The allele status (homozygous and heterozygous) of the ampilcons obatained from different samples, was analyzed by restriction with EcoR1.X-allele was responsible for absence of EcoR1 site and $\mathrm{X}+$ allele was responsible for the presence of EcoR1 site. But for both cases the flanking region of gene segments were same,hence both types of allele was amplified. If $\mathrm{X}-\mathrm{X}$ - allele was present, $400 \mathrm{bp}$ was obtained. If $\mathrm{X}+\mathrm{X}$-allele was present, three bands $400 \mathrm{bp}, 253 \mathrm{bp}, 227 \mathrm{bp}$ were obtained. $(\mathrm{X}+\mathrm{X}+$ homozygous condition for the presence of EcoR1,X-X- homozygous condition for the absence of EcoR1, and X+X- is heterozygous condition(Table.03).

\section{Allelic status of Group I}

Sampleno1,3,4,5,7,8,11,12,13,16,17,19,21,22,23,35,26,29,30,31,34,35,39,40,41,43,44,47,48,49,52,53.of group I had allelic status $\mathrm{X}+\mathrm{X}+$, sample no. 6,10,18,24,28,36,42,46,54 of group I had allelic status X-X-,sample no.2,9,14,15,32,33,38,45,50,51 of group I had allelic status $X+X$-(fig.9,10,11)

\section{Allelic status of Group I}

Sample no $1,2,5,6,8,10,11,16,17,18,19,22,23,25,27,28,29,30,31,34,35,36$

$39,40,41,47,48,49,53$ of group II had allelic status X+X+, Sample no.42,46

50,51 of group II had allelic status X-X- ,Sample no.3,4,7,9,12,13,14,20,21,

$24,26,32,33,37,38,43,44,45,52,54$ of group II had allelic status $\mathrm{X}+\mathrm{X}-$.

\section{Correlation of ApoB gene and hyperlipidemia}

The correlation of $\mathrm{X}+(\mathrm{X}+\mathrm{X}+$ and $\mathrm{X}+\mathrm{X}-)$ and $\mathrm{X}-(\mathrm{X}-\mathrm{X}-)$ and lipid value was determined by the $r$ value (correlation coefficient).

$$
\mathbf{R}=\begin{aligned}
& \sum x y-\sum x+\sum y / n \\
& {\left[\sum \mathbf{x}-\left(\sum \mathbf{x}\right) / \mathbf{n}\right]\left[\sum \mathbf{y}-\left(\sum \mathbf{y} / \mathbf{n}\right]\right.}
\end{aligned}
$$




\section{Correlation in case if group I}

In order to find out correlation between $\mathrm{ApoB}$ gene polymorphism and higher levels of either serum $\mathrm{Tc}$ or $\mathrm{Tg}$, different allele condition were assumed as-

For X-X- (Homozygous condition, restriction site absent)-0

For $\mathrm{X}-\mathrm{X}+$ and $\mathrm{X}+\mathrm{X}-($ homozygous and heterozygous condition respectively, restriction site present) -2 .

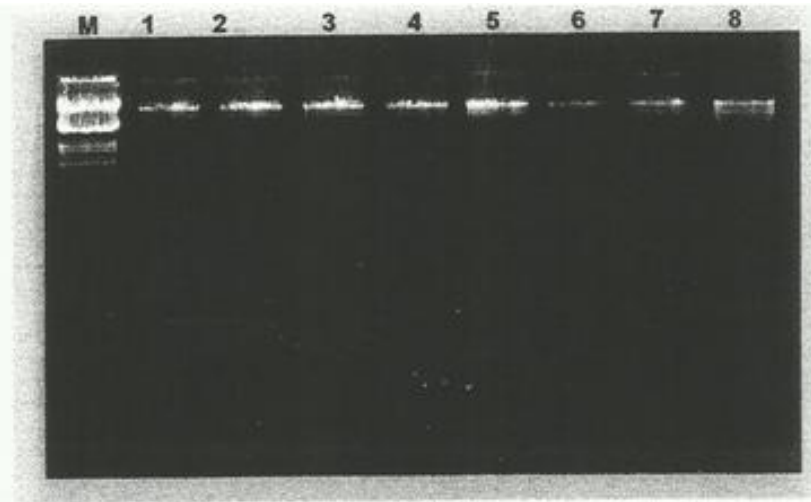

Fig1. : Genomic DNA of control.

M : lamda Eco R//Hind III double digest.

Lane 1-8 : Genomic DNA of control 1-control 8

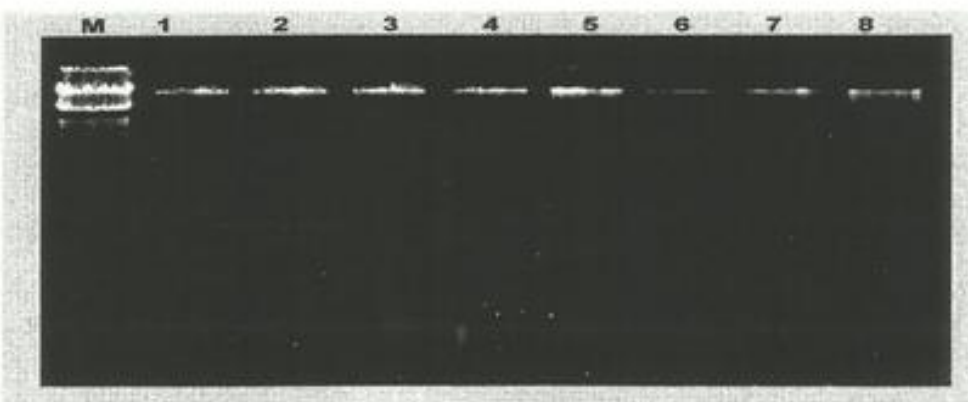

Fig2 : Genomic DNA of case.

M : Lamda Eco Ri/Hind III double digest.

Lane 1-8 : Genomic DNA of case 1-case 8.(single base pair)

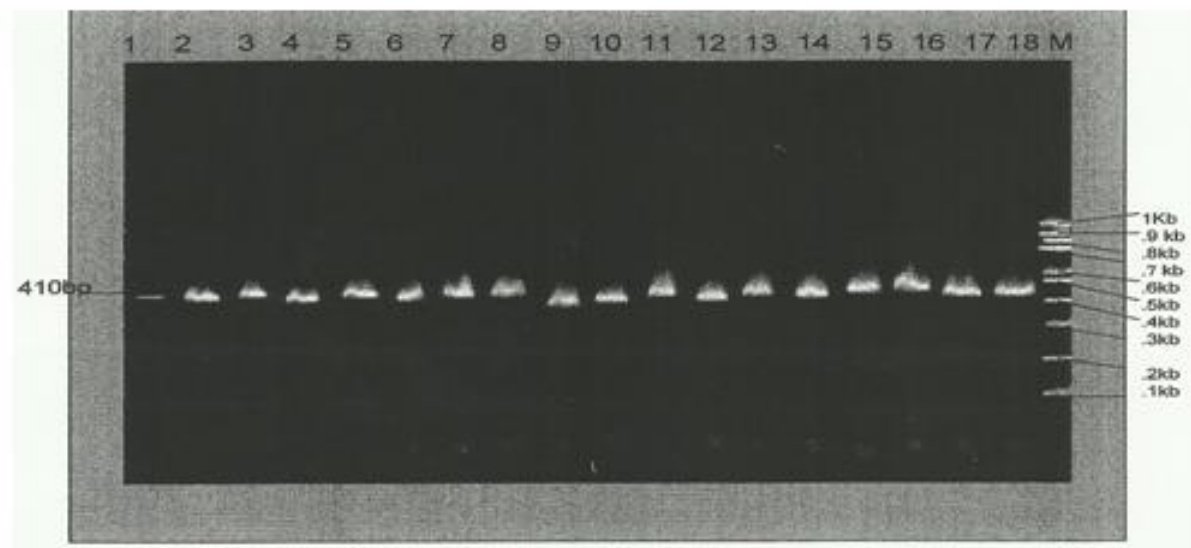

Fig 3 :PCR amplification of apolipoprotein B gene using primer specific for EcoRI site.

M :100 bp ladder.

Mane 1-8. Amplicons of control 1-18 


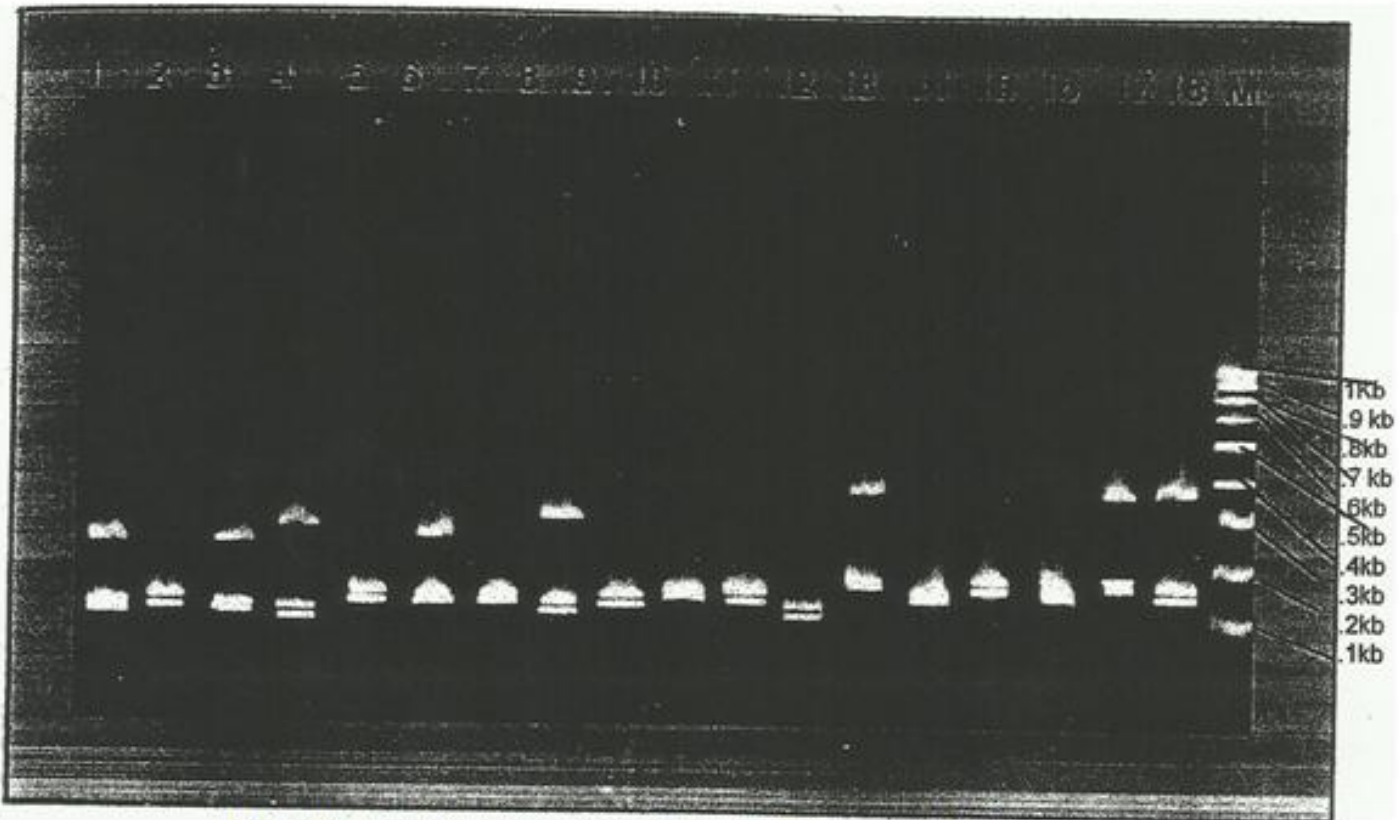

Fig: 4 Restriction digestion of cases using restriction enzyme EcoR1

\section{M: lamda/hind HI/EcoRl double digest}

\section{ML: 100 bp ladder}

Lane1: RD of Case1 (3bands- 700bp ,400bp. 300bp)

Lane2: RD of Case 2 ( 2 bands- $400 \mathrm{bp}, 300 \mathrm{bp}$ )

Lane3: RD of Case 3 (3bands- $700 \mathrm{bp} .400 \mathrm{bp} .300 \mathrm{bp}$ )

Lane4: RD of Case 4 (3 bands- $700 \mathrm{bp}, 400 \mathrm{bp}, 300 \mathrm{bp}$ )

Lane5: RD of case 5 ( 2 bands- $400 \mathrm{bp} .300 \mathrm{bp}$ )

Lane 6: RD of case 6 (3band- 700 bp. $400 \mathrm{bp} .300 \mathrm{bp}$ )

Lane 7: RDof case7 ( 2 bands-400tp. 300 bp)

Lane 8: RD of case 8 ( 3 bands- 700bp, 400 bp 300 bp)

Lane 9: RD of case9 (2bands-4000p. $300 \mathrm{bp}$ )
Lane 10: RD of case10(2 band 400bp, 300bp) Lane 11: RD of case 11 ( 2 bands 400 bo, $300 \mathrm{bp}$ ) Lane $12 \mathrm{RD}$ of case 12 ( 2 bands- $400 \mathrm{bp}, 300 \mathrm{bp}$ ) Lane 13: RD of case13(2 bands:400bp.300b Lane 14: RD of case 14(2band, $400 \mathrm{bp}, 300 \mathrm{bp}$ ) Lane 15: RD of case 15 ( 2 band $400 \mathrm{bo}, 300 \mathrm{bp}$ ) Lane 16: RD of case 16 ( 2 bands $-400 \mathrm{bp}, 300 \mathrm{bp}$ ) Lane 17: RD of case 17 (3bands. $700 \mathrm{bp} .400 \mathrm{bp} .3 \mathrm{C}$ Lane 18: RD of case 18 ; 3 band $-700 \mathrm{bp} .400 \mathrm{bp} .30 \mathrm{C}$

Table 3: Restriction analysis of Amplicons.

\begin{tabular}{|l|l|l|l|l|}
\hline Allele Condition & Expected Bands & $\begin{array}{l}\text { Expected Size in base } \\
\text { Pair }\end{array}$ & Observed Bands & $\begin{array}{l}\text { Observed Size in Base } \\
\text { Pair }\end{array}$ \\
\hline $\mathbf{X}-\mathbf{X}-$ & 1 & 400 & 1 & 400 \\
\hline $\mathbf{X}+\mathbf{X}+$ & 2 & 253,227 & 2 & 253,227 \\
\hline $\mathbf{X}+\mathbf{X}-$ & 3 & $400,253,227$ & 3 & $400,253,227$ \\
\hline
\end{tabular}

(Tabble.4) Allele frequencies of homozygous and heterozygeous individuals were obtained by gene counting

\begin{tabular}{|l|l|l|l|l|l|}
\hline & $\mathbf{X + X +}$ & $\mathbf{X}+\mathbf{X}-$ & $\mathbf{X}-\mathbf{X}-$ & $\mathbf{X}-$ & $\mathbf{X}-$ \\
\hline Group I & $27 / 54$ & $21 / 54$ & $4 / 54$ & $49 / 54$ & $27 / 54$ \\
\hline Frequency & 0.52 & 0.38 & 0.04 & 0.90 & 0.50 \\
\hline GroupII & $24 / 54$ & $23 / 54$ & $6 / 54$ & $48 / 54$ & $22 / 54$ \\
\hline Frequency & 0.44 & 0.42 & 0.11 & 0.88 & 0.40 \\
\hline
\end{tabular}

*By comparing allelic frequencies it is found that the frequency of $\mathrm{X}+$ and $\mathrm{X}$ - in group I were 0.90 and 0.50 respectively and in group II were 0.88 and 0.40 respectively.

*By comparing them it was found that there was no significant difference between the two groups.

$\mathbf{R}=$

$$
\sum x y-\sum x \cdot \sum y / n
$$

$$
\left[\sum \mathbf{x}-\left(\sum \mathbf{x}\right) / \mathbf{n}\right]\left[\sum \mathbf{y}-\left(\sum \mathbf{y} / \mathbf{n}\right]\right.
$$

$\mathrm{r}$ value calculated by the above formula gave value 0 , this signifies no correlation between allelic condition and lipid value of group I (Hyperlipidemic subjects).

Similarly correlation between allelic conditions and lipid value of group II (normolipidemic subjects) ,the $r$ value calculated also gave value 0 . 


\section{Conclusion}

No correlation was observed betweeb allelic condition and hyperlipidemia and allelic condition and normolipidemia, therefore it eas concluded that there was no correlation of allelic frequencies of polymorphism between hyperlipidemic and normolipidemic subjects.

\section{Refrences}

[1]. Cornfield J, Mitchell S. Selected risk factors in coronary disease. Possible intervention effects. Arch Environ Health. 1969 Sep;19(3):382-394.

[2]. OslerW. The Lumleian lectures on angina pectoris. Lancet. 1892;1:829-844

[3]. Avogaro P., Bittolo Bon G., Cazzolato G., Quinci G.B., Sanso A., Sparla M., Zagatti G/C/, Caturelli G. (1978): Variations in apolipoproteins B and A-I in the course of acute myocardial infarction. Europ. J. Clin. Invest., 8, 121

[4]. Berg K, Hames C, Dahlén G, Frick MH, Krishan I. Genetic variation in serum low density lipoproteins and lipid levels in man. Proc Natl Acad Sci U S A. 1976 Mar;73(3):937-940

[5]. Chen,W.-J.,J,Goldstein, and M.S.Brown.1990.NPXY,a sequence often found in cytoplasmic tails, is required for coated pit-mediated internalization of the low density lipoprotein receptor . J.Biol Chem .265:3116-3123.

[6]. Law SW, Grant SM, Higuchi K, Hospattankar A, Lackner K, Lee N, Brewer HB., Jr Human liver apolipoprotein B-100 cDNA: complete nucleic acid and derived amino acid sequence. Proc Natl Acad Sci U S A. 1986 Nov;83(21):8142-8146.

[7]. Law A, Wallis SC, Powell LM, Pease RJ, Brunt H, Priestley LM, Knott TJ, Scott J, Altman DG, Miller GJ, et al. Common DNA polymorphism within coding sequence of apolipoprotein B gene associated with altered lipid levels. Lancet. 1986 Jun 7;1(8493):1301-1303.

[8]. Ludwig EH, Blackhart BD, Pierotti VR, Caiati L, Fortier C, Knott T, Scott J, Mahley RW, Levy-Wilson B, McCarthy BJ. DNA sequence of the human apolipoprotein B gene. DNA. 1987 Aug;6(4):363-372.

[9]. Paul weber B Frled 1 W, Krempler F, Humphries S E, Sandhofer F. Genetic variation in the apo lipoprotein Al-CIII-AIV gene cluster and coronary heart disease. Athero-sclerosis 1988:73:125-133

[10]. Clayton D, McKeigue PM. Epidemiological methods for studying genes and environmental factors in complex diseases. Lancet. 2001;358(9290):1356-1360

[11]. Smith GD, Ebrahim S. "Mendelian randomization": can genetic epidemiology contribute to understanding environmental determinants of disease? Int J Epidemiol. 2003;32(1):1-22

[12]. Smith GD, Ebrahim S. Mendelian randomization: prospects, potentials, and limitations. Int J Epidemiol. 2004;33(1):30-42

[13]. Boerwinkle E, Lee SS, Butler R, Schumaker VN, Chan L (1990) Rapid typing of apolipoprotein B DNA polymorphisms by DNA amplification. Atherosclerosis 81:225-232

[14]. Bennett C, Crawford F, Osborne A, Diaz P, Hoyne J, Lopez R, Roques P, Duara R, Rossor M, Mullan M (1995) Evidence that the ApoE locus advances disease progression in late onset familial Alzheimer's disease but is not causative. Am J Med Genet 60:1-6

[15]. Talmud PJ, Barni N, Kessling AM, Carlsson P, Darnfors C, Bjursell G, Galton D, Wynn V, Kirk H, Hayden MR, et al. Apolipoprotein B gene variants are involved in the determination of serum cholesterol levels: a study in normo- and hyperlipidaemic individuals. Atherosclerosis. 1987 Sep;67(1):81-89.

[16]. Renges H H , Wile D B , McKeiguePM , Marmot MG , Humphries S E. Apolipoprotein B gene polymorphisms are associated with lipid levels in men of South Asian descent.Atherosclerosis 1991;91:267-275

[17]. Saha N ,Tay JS ,Heng CK,Humphries SE. DNA Polymorphism of the apolipoprotein B gene are associated with obesity and serum lipid in healthy Indians in Singaore.Clin Genet 1993;44:113-120

[18]. Low PS,Heng CK, Saha N Tay JSH .Racial Variation of Cord Plasma Lipoprotein(a) Levels in Relation to Coronary Risk Level: A Study in Three Ethnic Groups in Singapore 